\title{
EMPATI AFEKTIF: MEDIATOR PENGARUH KETERLIBATAN ORANG TUA TERHADAP PERAN DEFENDER REMAJA DALAM PERUNDUNGAN DI SEKOLAH
}

\author{
Charyna Ayu Rizkyanti ${ }^{1 *}$, Ade Iva Murty ${ }^{1}$, Natacia Revana Paramaharta ${ }^{1}$
}

${ }^{1}$ Fakultas Psikologi, Universitas Pancasila, Jakarta, 12640, Indonesia

*)E-mail: charyna@univpancasila.ac.id

\begin{abstract}
Abstrak
Perundungan di sekolah telah menjadi suatu hal yang lazim sekarang ini meskipun bahaya perundungan terhadap perkembangan anak sudah cukup disadari. Tujuan dari penelitian ini adalah untuk menganalisis pengaruh keterlibatan orang tua terhadap peran defender yang dimediasi oleh empati pada remaja dalam peristiwa perundungan di sekolah. Penelitian melibatkan 320 remaja (siswa SMP kelas 7 hingga 9) dengan rentang usia $12-15$ tahun (52,5\% perempuan dan $47,5 \%$ laki-laki) yang dipilih melalui teknik accidental sampling. Setiap partisipan diberi tiga alat ukur, yaitu keterlibatan orang tua, empati, dan peran defender dalam kasus perundungan di sekolah. Data dianalisis dengan menggunakan teknik Confirmatory Factor Analysis (CFA) dan proses Hayes Model 4. Hasil penelitian menunjukkan bahwa semakin tinggi keterlibatan orang tua dalam kehidupan anak remajanya maka kecenderungan anak untuk menjadi defender pun semakin tinggi. Selain itu, empati afektif berpengaruh lebih kuat secara positif pada peran defender dibandingkan empati kognitif. Lebih jauh, hanya empati afektif yang memediasi secara parsial hubungan keterlibatan orang tua pada peran defender. Temuan penelitian menunjukkan bahwa orang tua perlu terlibat secara aktif di kehidupan remaja terutama dalam mengembangkan empati anak remajanya, khususnya empati afeksi, agar anak remaja mampu memilih peran sebagai defender untuk membela korban peristiwa perundungan di sekolah.
\end{abstract}

Kata kunci: empati afektif-kognitif, keterlibatan orang tua, peran defender, perundungan di sekolah, remaja

\section{The Affective Empathy: The Mediator of Influence of Parent Involvement on the Role of Youth Defenders in School Bullying}

\begin{abstract}
Bullying at school has become a common thing nowadays, even though the dangers of bullying to child development are well recognized. The purpose of this study was to analyze the effect of parental involvement on the role of defender mediated by empathy in adolescents in bullying at school. The study involved 320 adolescents (junior high school students grades 7 to 9) with an age range of $12-15$ years (52,5\% female and $47,5 \%$ male) who was selected through the accidental sampling technique. Each participant was given three measuring tools, namely parental involvement, empathy, and the role of the defender in cases of bullying at school. The data were analyzed using the Confirmatory Factor Analysis (CFA) technique and the Hayes Model 4 process. The results showed that the higher the involvement of people in the lives of adolescents, the higher the tendency of children to become defenders. In addition, affective empathy has a stronger positive effect on the defender role than cognitive empathy. Furthermore, only affective empathy partially mediates the relationship between parental involvement in the defender role. The research finding shows that parents need to be actively involved in the lives of adolescents, especially in developing adolescent empathy, especially affection empathy, so that adolescents are able to choose the role of the defender to defend victims of bullying at school.
\end{abstract}

Keywords: affective-cognitive empathy, defender role, early adolescents, parental involvement, school bullying

\section{PENDAHULUAN}

Angka perundungan di Indonesia dengan angka $41 \%$ dilaporkan terjadi beberapa kali dalam sebulan (KPAI, 2019). Peristiwa perundungan ini kerap berlaku di sekolah, bahkan dalam kelas (Damanik \& Djuwita, 2017). Sekolah yang seharusnya merupakan tempat untuk belajar, bersosialisasi, dan bermain sekarang beralih menjadi tempat yang tidak aman untuk para siswa. Penelitian Marela, Wahab, dan Marchira (2017) menemukan bahwa remaja yang mengalami perundungan berpeluang 1,5 kali lebih besar mengalami depresi dibandingkan dengan remaja yang tidak mengalami perundungan. Lebih jauh lagi, 
korban bahkan diketahui memiliki keinginan atau berusaha untuk bunuh diri (Koyanagi et al., 2019; Vergara, Stewart, Cosby, Lincoln, \& Auerbach, 2019;).

Menurut Solberg dan Olweus (2003), perundungan (bullying) adalah jenis agresi proaktif yang berbeda dengan ciri adanya ketidakseimbangan kekuatan antara pelaku dan korban, serta biasanya melibatkan pengulangan. Bentuk tindakan perundungan di antaranya yaitu pelecehan verbal, agresi fisik, dan korban relasional (Rothon, Head, Klineberg, \& Stansfeld, 2011). Smokowski dan Kopazs (2005) menjelaskan bahwa perundungan merupakan bentuk kekerasan pada anak dan berpotensi meluas menjadi bentuk antisosial yang lebih ekstrim.

Dampak buruk bagi korban meliputi kesehatan fisik (Gini, Pozzoli, Vieno, \& Lenzi, 2014) maupun mental, misalnya penyesuaian psikososial (Card, Stucky, Sawalani, \& Little, 2008). Selain korban dan pelaku, peristiwa perundungan dapat menimbulkan bentuk trauma interpersonal yang berdampak pada semua orang yang terlibat dalam situasi itu, termasuk remaja/siswa yang ikut menyaksikan peristiwa tersebut (Lambe, Hudson, Craig, \& Pepler, 2017). Selain trauma, anak yang terbiasa menyaksikan peristiwa kekerasan akan memandang kekerasan sebagai cara penyelesaian dalam menghadapi setiap masalah. Berbagai dampak buruk dari perundungan ini ternyata juga dialami oleh orang yang menyaksikan peristiwa ini seperti keluhan somatik, depresi, kecemasan, penggunaan narkoba, ketidakberdayaan, dan bahkan sampai memiliki ide bunuh diri (Rivers \& Noret, 2013).

Salmivalli (1999) mengkategorikan orang yang menyaksikan peristiwa perundungan tersebut (selain korban dan pelaku) ke dalam beberapa kelompok. Masing-masing kelompok memiliki peran di dalamnya, yaitu sebagai assistant, reinforcer, outsider, dan defender. Diantara sejumlah peran yang dapat diambil siswa ketika menghadapi peristiwa perundungan maka ada satu peran penting yang berpotensi besar untuk menghentikan peristiwa perundungan terjadi, yaitu peran sebagai pembela (defender). Bellmore, Ma, You, dan Hughes (2012) menjelaskan bahwa defender adalah siswa yang memberikan bantuan kepada korban perundungan agar korban tidak mengalami stres dan permasalahan serius lainnya. Motivasi yang timbul dalam diri untuk membantu korban perundungan yang membuat remaja merasa gelisah apabila hanya menjadi pengamat pasif, inilah yang memotivasi defender (Jungert, Piroddi, \& Thornberg, 2016).

Siswa yang merasa enggan mencari bantuan untuk menolong korban ketika perundungan terjadi antara lain karena merasa bahwa hal tersebut memalukan dan mereka nantinya berpotensi untuk terkena risiko berupa sindiran maupun penghinaan (Bellmore et al., 2012). Siswa-siswa tersebut juga berpikir bahwa membela korban bukanlah urusannya, selain juga takut akan konsekuensi yang mungkin diterima. Namun, hal paling mengkhawatirkan adalah para siswa tersebut berpotensi untuk ikut menikmati tindakan perundungan yang disaksikannya (Rigby \& Johnson, 2005). Artinya, terlibat secara langsung ataupun hanya melihat peristiwa perundungan dapat memberikan dampak tersendiri bagi siapapun yang ada di sekitar kejadian tersebut.

Penelitian mengenai mengenai peran defender pada remaja di Indonesia telah dilakukan oleh Damanik dan Djuwita (2019). Penelitian tersebut melibatkan sebanyak 138 mahasiswa tingkat pertama yang berasal dari berbagai SMA di Indonesia terlibat dalam penelitian ini. Hasil penelitian ini mendapati bahwa tindakan para defender saat melihat peristiwa perundungan adalah membela korban $(55,10 \%)$, melaporkan ke orang dewasa $(53,60 \%)$, mencari bantuan siswa lain $(55,10 \%)$, maupun mendukung korban setelah peristiwa perundungan (69,60\%). Namun, diketahui juga bahwa sebagian besar dari partisipan memilih untuk tidak melakukan apaapa dengan cara meninggalkan lokasi kejadian, menonton, berdiam, atau bahkan tertawa.

Beberapa hasil penelitian lain, khususnya di luar Indonesia, penelitian mengenai peran defender dengan peran orang tua lebih banyak dikaitkan dalam konteks dukungan orang tua (Lambe et al., 2017; Padilla-Walker, Carlos, Christensen, \& Vorgason, 2012), kelekatan (Nickerson, Mele, \& Princiotta, 2008), dan harapan orang tua (Pozzoli \& Gini, 2013). Hasil penelitian lainnya lebih menekankan bahwa peran orang tua yang positif sangat penting untuk menstimulasi perkembangan emosi moral (Ngai, Xie, Ng \& Ngai, 2018). Berdasarkan sejumlah hasil penelitian tersebut dapat ditarik kesimpulan bahwa keterlibatan orang tua sangat penting dalam kehidupan remajanya, khususnya dalam peran anak sebagai defender dalam kasus-kasus perundungan.

Keluarga merupakan mikrosistem yang paling dekat bagi anak dalam menciptakan peran sebagai defender. Keterlibatan orang tua 
merujuk pada sejauh mana orang tua merasa tertarik, mengetahui, dan berpartisipasi aktif dalam kehidupan anaknya (Robbins, 1994). Hasil penelitian Cho, Glassner, dan Lee, (2019) menemukan bahwa remaja usia 11-15 tahun di Korea Selatan dengan tingkat keterlibatan orang tua yang lebih rendah memiliki peluang besar untuk melakukan perundungan. Biasanya, remaja laki-laki lebih banyak menjadi pelaku perundungan. Stives, May, Pilkinton, Bethel, dan Eakin (2018) menyatakan bahwa meskipun telah banyak penelitian yang membahas mengenai topik perundungan, masih sangat kurang informasi tentang sejauh mana tanggapan dan kesadaran orang tua terkait perundungan yang dialami anaknya.

Penelitian yang dilakukan oleh Valdés-Cuervo, Alcantar-Nieblas, Martinez-Ferrer, dan ParraPerez (2018) mengenai keterlibatan orang tua dengan peran sebagai defender pada remaja berusia 11-15 tahun di Meksiko mendapati bahwa lingkungan keluarga yang positif dan penerapan disiplin oleh orang tua dapat mendukung remaja untuk menjadi defender dalam perundungan. Keterlibatan orang tua membuat anak mampu menginterpretasi dengan baik keinginan maupun harapan orang tuanya terkait cara untuk menhgadapai peristiwa perundungan yang ia saksikan (Patterson, Allan, \& Cross, 2017; Pronk, Olthof \& Gossens, 2015). Oleh karenanya, orang tua perlu terlibat dalam memberikan dukungan pada anak untuk menghadapi peristiwa perundungan, terutama mengambil tindakan tepat dalam membantu kawannya yang menjadi korban perundungan.

Dalam kasus perundungan, orang tua yang menumbuhkan rasa kepedulian seperti empati, kenyamanan, emosi, dan kasih sayang kepada anaknya akan membuat anak dapat menyalurkan hal yang sama kepada orang lain pula (Lai, Siu \& Shek, 2015). Orang tua yang melibatkan diri secara intens dengan anaknya akan membuat anak merasa dipedulikan, diperhatikan, dan mengetahui bahwa anak akan selalu memiliki tempat untuk kembali. Nilai-nilai yang diterapkan orang tua pada anak mampu menjadikan anak peka terhadap keinginan dan harapan orang tua, termasuk dalam menghadapi peristiwa perundungan. Thornberg et al. (2012) menyatakan bahwa siswa yang menolong korban memiliki persepsi bahwa orang dewasa, seperti orang tua dan guru, ingin dirinya melakukan intervensi terhadap peristiwa perundungan. Dengan kata lain, kemampuan anak untuk memahami dan merasakan harapan dari orang tua maupun sekitarnya semakin berkembang ketika anak menolong anak lain yang mengalami perundungan.

Kemampuan untuk memahami apa yang dirasakan orang lain merupakan definisi ringkas dari empati (Jolliffe \& Farrington, 2006). Dalam fenomena kekerasan (termasuk perundungan), telah terpostulasikan bahwa perilaku kekerasan sangat berkaitan dengan rendahnya kemampuan dalam berempati. Sejalan dengan berkembangnya penelitian tentang empati maka saat ini terdapat dua dimensi yang seringkali digunakan, yaitu dimensi kognitif dan afektif (Lawrence, Shaw, \& Baker, 2004). Empati kognitif yang tinggi membuat individu dapat memahami sudut pandang dan reaksi emosi orang lain, sedangkan empati afektif membuat individu mampu merasakan emosi atau perasaan orang lain. Berlawanan dengan empati afektif yang diketahui dapat memotivasi perilaku prososial dan menurunkan perilaku agresif, empati kognitif dapat dimanfaatkan oleh pelaku perundungan (Jolliffe \& Farrington, 2006), misalnya pelaku dapat menggunakan kemampuan tersebut untuk melakukan intimidasi dan mengajak orang lain untuk terlibat dalam tindakan perundungan.

Bellmore et al. (2012) menjelaskan bahwa perilaku siswa yang memilih untuk membantu korban perundungan didorong oleh beberapa alasan yang berbeda, diantaranya yaitu siswa mau membela korban perundungan karena mereka memiliki perasaan empati atau perhatian terhadap korban sehingga ingin menunjukkan kepeduliannya. Secara intrinsik, seseorang yang memilih peran sebagai defender dimotivasi oleh faktor internal yaitu empati (Thornberg et al., 2012). Lebih lanjut, semakin banyak siswa yang berani menjadi defender di sekolah diharapkan dapat mencegah terjadinya perundungan, bahkan harapan seterusnya adalah agar para defender ini akan tetap menjadi pembela korban pada tingkatan sekolah selanjutnya.

Sejauh ini lebih banyak literatur yang membahas peran defender dan mengaitkannya dengan karakteristik individual (Datta, Cornell \& Huang, 2016; Jenkins, Demaray, Frederick, \& Summers, 2016), hubungan dengan teman sebaya (Gini, Pozzoli \& Bussey, 2014; Van der Ploeg, Kretschmer, Salmivalli \& Veenstra, 2017), dan konteks sekolah (Jungert et al., 2016; Storer, Casey, \& Herrenkohl, 2017). Penelitian sebelumnya telah meneliti hubungan antara peran orang tua maupun empati terhadap peran defender, namun belum ada studi yang secara langsung mengaitkan melalui proses mediasi empati terhadap hubungan 
antara keterlibatan orang tua dan peran defender terutama pada usia remaja awal. Padahal, berdasarkan sejumlah hasil penelitian diketahui bahwa anak-anak yang berusia lebih muda, misal di tingkat sekolah dasar (SD) lebih berani untuk menjadi defender dibandingkan anak-anak usia di atasnya (Bellmore et al., 2012).

Penelitian ini dilakukan dengan mempertimbangkan bahwa peran orang tua pada anak usia SD masih sangat terlibat, namun selanjutnya mulai melemah saat anak beranjak remaja dan dewasa. Sementara itu, telah terpostulasikan bahwa peran untuk menjadi defender sangat bergantung kepada keterlibatan orang tua dalam mengembangkan potensi anaknya untuk berempati. Oleh karenanya, mengingat bahwa peran defender dipercaya mampu mengurangi peristiwa perundungan serta dapat meringankan efek seumur hidup pada para korban yang terlibat dalam perundungan maka keluarga perlu terlibat dalam kehidupan anaknya agar dapat terus memperkuat peranan defender dimanapun anak berada, termasuk di sekolah. Berdasarkan pemaparan sebelumnya maka penelitian ini bertujuan menganalisis pengaruh keterlibatan orang tua terhadap peran anak sebagai defender yang dimediasi oleh empati dalam peristiwa perundungan pada siswa Sekolah Menengah Pertama (SMP).

\section{METODE}

Penelitian ini menggunakan desain crosssectional study yang dilakukan di Jakarta dengan pertimbangan catatan KPAI pada tahun 2019 bahwa Jakarta merupakan kota yang paling banyak didapati laporan terjadinya peristiwa perundungan. Penelitian dilakukan di tiga sekolah (2 SMP negeri dan 1 SMP swasta). Pemilihan dilakukan secara accidental dengan alasan bahwa telah diakui bahwa semua sekolah di dunia memiliki potensi terjadinya perundungan (Rigby \& Johnson, 2006).

Populasi penelitian ini adalah remaja SMP di Jakarta kelas 7 hingga kelas 9 yang merupakan pelajar aktif. Peneliti menggunakan siswa SMP sebagai partisipan karena penelitian sebelumnya lebih banyak menyoroti siswa SMU yang terlibat dalam kasus perundungan, terutama sebagai pelaku dan bystander, bukan sebagai defender. Penelitian sebelumnya menyatakan bahwa hubungan yang buruk dengan orang tua di tahap remaja awal ini merupakan prediktor utama dari munculnya perilaku perundungan (Erginoz et al., 2013; Espelage, 2014) sehinga sangat penting untuk meneliti usia remaja awal (siswa SMP) terkait perannya sebagai defender sebagai upaya pencegahan perilaku perundungan yang lebih masif. Jumlah partisipan pada penelitian ini sebanyak 320 orang siswa. Data dikumpulkan melalui kuesioner terstruktur. Data primer yang dikumpulan meliputi karakteristik siswa, keterllibatan orang tua, empati siswa, dan peran sebagai defender.

Peran defender dalam peristiwa perundungan adalah siswa SMP yang menempatkan dirinya sebagai seseorang yang terlibat untuk menolong korban dalam peristiwa perundungan. Kuesioner yang digunakan untuk peran defender dalam perundungan menggunakan alat ukur Participant Roles Scale yang dikembangkan oleh Salmivalli, Lagerspetz, Björkqvist, Österman, dan Kaukiainen (1996) melalui 20 pernyataan. Alat ukur ini diterjemahkan kemudian dilakukan expert judgement.

Berdasarkan hasil expert judgement, semua materi instrumen telah sesuai dengan konsep yang akan diukur. Pada alat ukur Participant Roles Scale ini partisipan diminta untuk memilih salah satu dari empat alternatif pilihan jawaban yang disusun berdasarkan skala Likert 1 sampai dengan 4. Rentang skala mulai dari 1 untuk "Sangat Tidak Setuju (STS)", 2 untuk "Tidak Setuju (TS)", 3 untuk "Setuju (S)" dan 4 untuk "Sangat Setuju (SS)". Peneliti melakukan uji alat ukur dengan teknik Confirmatory Factor Analysis (CFA). Pada skala defender ini terdapat 12 pernyataan yang valid dengan nilai factor loading berkisar antara 0,30-0,68 dan nilai Estimated Reliability (ER) sebesar 0.88 . Alat ukur ini memiliki indikator fit yang baik $(x 2$ $=59,78, \mathrm{df}=51, \mathrm{p}=0,18706, \mathrm{RMSEA}=0,023$, $\mathrm{GFI}=0,97)$.

Sementara itu, keterlibatan orang tua merupakan cara yang dilakukan oleh orang tua dalam mendukung dan melibatkan diri dalam kehidupan anaknya. Keterlibatan orang tua diukur melalui Perceptions of Parents Scale (POPS) yang dikembangkan oleh Robbins (1994) yang terdiri atas 21 pernyataan. Pada alat ukur ini terdapat tiga dimensi, yaitu dimensi autonomy support (dukungan autonomi), parenting (pengasuhan), dan warmth (kehangatan yang diberikan). Alat ukur ini diterjemahkan kemudian dilakukan expert judgement.

Hasil expert judgement menunjukkan bahwa semua materi instrumen telah sesuai dengan konsep yang akan diukur. Responden diminta untuk memilih salah satu dari empat alternatif 
pilihan jawaban yang disusun berdasarkan skala Likert 1 sampai dengan 4 . Rentang skala mulai dari 1 untuk "Sangat Tidak Setuju (STS)", 2 untuk "Tidak Setuju (TS)", 3 untuk "Setuju (S)", dan 4 untuk "Sangat Setuju (SS)". Alat ukur ini memiliki unfavorable item yaitu pernyataan nomor 2, 6, 13, 14, 15, 20 dan 21. Berdasarkan uji alat ukur dengan teknik Confirmatory Factor Analysis (CFA), diperoleh hasil terdapat 11 pernyataan yang valid dengan nilai factor loading berkisar antara 0,38-0,66 dan nilai Estimated Reliability (ER) sebesar 0,89 . Alat ukur ini memiliki indikator fit yang baik $(x 2=98,11, d f=43, p=0,00000$, RMSEA $=0,063, \mathrm{GFI}=0,93)$.

Alat ukur yang digunakan untuk mengukur empati ialah Basic Empathy Scale (BES) yang dikembangkan oleh Jolliffe dan Farrington (2006). Basic Empathy Scale (BES) terdiri dari 20 pernyataan yang menilai empati kognitif ( 9 pernyataan) dan empati afektif (11 pernyataan). Alat ukur ini diterjemahkan kemudian dilakukan expert judgement. Adapun hasil expert judgement yaitu alat ukur dimodifikasi pada pilihan jawaban yang semula ada lima poin berdasar tipe skala Likert menjadi empat poin. Untuk teknik skoring pada skala empati, partisipan diminta untuk memilih satu dari empat pilihan jawaban yang terdapat pada alat ukur Basic Empathy Scale (BES). Peneliti menggunakan skala Likert 1 sampai dengan 4 rentang skala mulai dari 1 untuk "Sangat Tidak Setuju (STS)", 2 untuk "Tidak Setuju (TS)", 3 untuk "Setuju (S)", dan 4 untuk "Sangat Setuju (SS)".

Pada skala BES ini, peneliti melakukan uji $C F A$ berdasarkan dimensi yaitu dimensi afektif dan kognitif. Pada dimensi empati afektif terdapat delapan pernyataan yang valid dengan nilai factor loading berkisar antara 0,50-0,75 dan nilai Estimated Reliability (ER) sebesar 0,88. Alat ukur ini memiliki indikator fit yang baik $(\mathrm{X}=42,32, \mathrm{df}=17, \mathrm{p}=0,00060, \mathrm{RMSEA}=0,068$, $\mathrm{GFI}=0,97)$. Adapun hasil CFA pada dimensi empati kognitif didapati enam pernyataan yang valid dengan nilai factor loading berkisar antara 0,31-0,71 dan nilai Estimated Reliability (ER) sebesar 0,81 . Alat ukur ini memiliki indikator fit yang baik $(x 2=15,23, \quad d f=9, \quad p=0,08488$, RMSEA $=0,047, \mathrm{GFI}=0,96)$.

Selanjutnya, untuk menguji validitas dan reliabilitas alat ukur, peneliti menggunakan teknik analisis Confirmatory Technique Analysis (CFA). Selanjutnya, peneliti melakukan uji hipotesis menggunakan regresi berganda dan uji multivariat dengan proses Hayes Model 4.

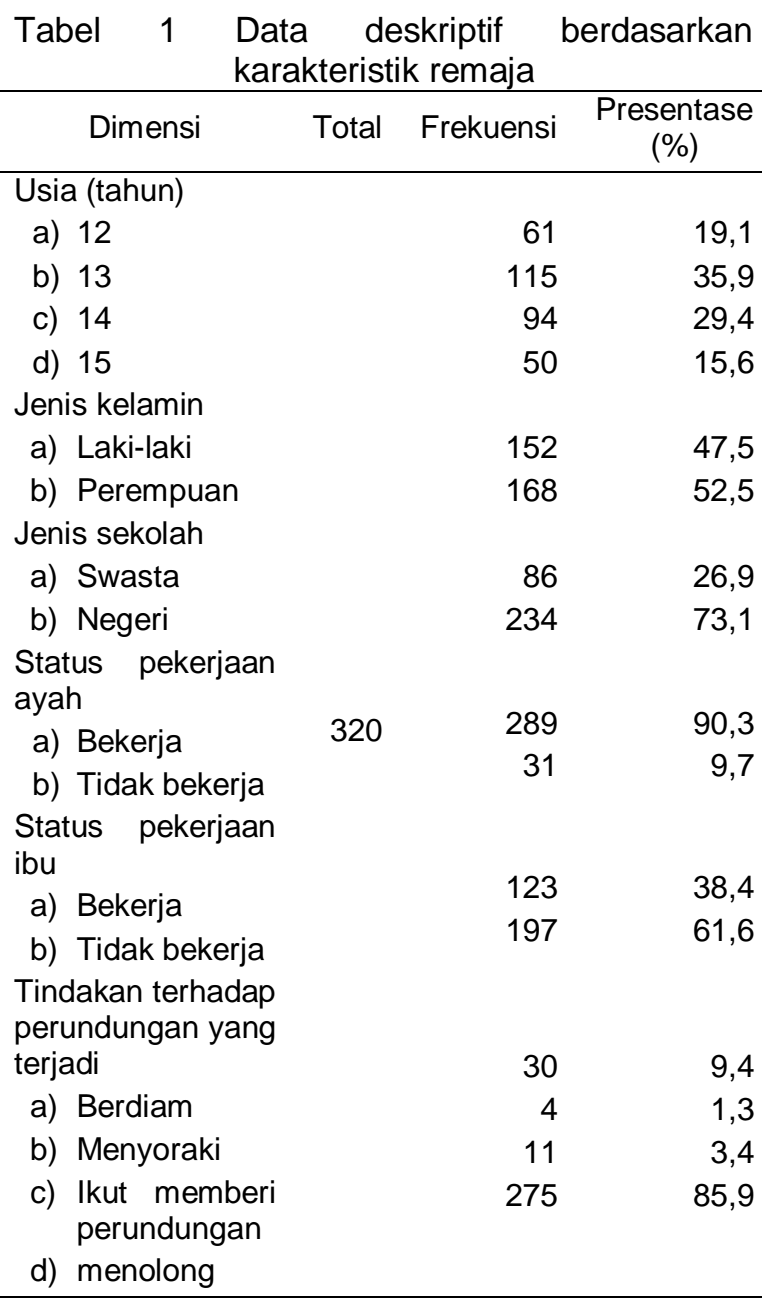

HASIL

Hasil penelitian menunjukkan bahwa dari 320 responden, remaja yang berusia 13 tahun paling tinggi sebanyak 115 orang. Selain itu, jenis kelamin perempuan mendominasi sebanyak 168 orang. Remaja yang bersekolah di sekolah negeri lebih tinggi $(73,1 \%)$ daripada yang bersekolah di sekolah swasta. Adapun tindakan remaja terhadap perundungan yang terjadi yaitu memberikan pertolongan sebanyak 224 orang (Tabel 1).

\section{Pengaruh Keterlibatan Orang Tua dan Empati Afektif terhadap Perilaku Defender}

Hasil analisis regresi (Tabel 2) menunjukkan bahwa keterlibatan orang tua memengaruhi perilaku defender sebesar 12,7 persen dengan $\mathrm{R} 2=0,127$. Keterlibatan orang tua secara positif memengaruhi perilaku defender dengan koefisien $\quad B=0,415, \quad p=0,000$. Artinya, peningkatan keterlibatan orang tua yang dirasakan seorang anak maka berpengaruh langsung terhadap peningkatan kemungkinan anak untuk melakukan perilaku defender. 
Tabel 2 Hasil uji regresi keterlibatan orang tua terhadap perilaku defender dan empati afektif terhadap perilaku defender

\begin{tabular}{|c|c|c|c|c|c|c|}
\hline \multirow{2}{*}{ Variabel bebas } & \multirow[t]{2}{*}{$R 2$} & \multicolumn{2}{|c|}{$\begin{array}{l}\text { Unstandardized } \\
\text { coefficents }\end{array}$} & \multirow{2}{*}{$\begin{array}{c}\text { Standardized } \\
\text { Coeffiecients (B) }\end{array}$} & \multirow[t]{2}{*}{$F$} & \multirow{2}{*}{$p$-value } \\
\hline & & $\beta$ & Standar Error & & & \\
\hline $\begin{array}{l}\text { Keterlibatan orang } \\
\text { tua }\end{array}$ & 0,127 & 0,415 & 0,096 & 0,357 & 18.680 & 0.000 \\
\hline Empati afektif & 0,21 & 0,334 & 0,050 & 0,348 & 43,829 & 0,000 \\
\hline
\end{tabular}

Sebaliknya, penurunan keterlibatan orang tua yang dirasakan seorang anak maka menyebabkan penurunan kemungkinan anak untuk melakukan perilaku defender. Selain itu, hasil yang tersaji pada Tabel 2 juga menunjukkan bahwa empati afektif memengaruhi defender sebesar 12,1 persen dengan $R 2=0,121$. Empati afektif secara positif memengaruhi defender dengan koefisien $B=0,334, p=0,000$.

Hasil tersebut menunjukkan bahwa peningkatan empati afektif yang dimiliki siswa akan menyebabkan peningkatan kecenderungan siswa untuk menunjukkan perilaku defender. Sebaliknya penurunan empati afektif yang dimiliki siswa akan menyebabkan penurunan kecenderungan siswa untuk menunjukkan perilaku defender.

Selanjutnya, hasil analisis seperti yang tersaji pada Gambar 1 menunjukkan bahwa keterlibatan orang tua masih berpengaruh lebih kuat dan positif terhadap perilaku defender dengan $B=0,3268, t=3,5566, p<0,01$. Nilai indirect effect membuktikan bahwa empati afektif hanya memediasi sebagian hubungan keterlibatan orang tua dengan defender dengan nilai $B=0,0504, L L C l=0,0122, \mathrm{ULCl}=0,1070$. Hal ini bermakna bahwa keterlibatan orang tua tetap memiliki pengaruh langsung terhadap perilaku defender meski terdapat pengaruh mediasi dari empati afektif.

Pengaruh Keterlibatan Orang Tua dan Empati Kognitif terhadap Perilaku Defender

Hasil analisis regresi yang tersaji pada Tabel 3 memperlihatkan bahwa keterlibatan orang tua memengaruhi perilaku defender sebesar 12,7 persen dengan $\mathrm{R} 2=0,127$. Keterlibatan orang tua secara positif memengaruhi perilaku defender dengan koefisien $B=0,415, p=0,000$. Artinya, semakin tinggi keterlibatan orang tua yang dirasakan seorang anak maka semakin tinggi kemungkinan untuk melakukan perilaku defender. Sebaliknya, semakin rendah keterlibatan orang tua yang dirasakan seorang anak maka semakin rendah kemungkinan untuk melakukan perilaku defender.

Empati kognitif memengaruhi defender sebesar 3,8 persen dengan $R 2=0,038$. Empati kognitif secara positif memengaruhi defender dengan koefisien $B=0,310, p=0,000$. Hasil tersebut menunjukkan bahwa semakin tinggi empati kognitif yang dimiliki siswa, maka siswa akan cenderung menunjukkan perilaku defender. Sebaliknya, semakin rendah empati kognitif yang dimiliki siswa, maka siswa akan cenderung enggan menunjukkan perilaku defender.

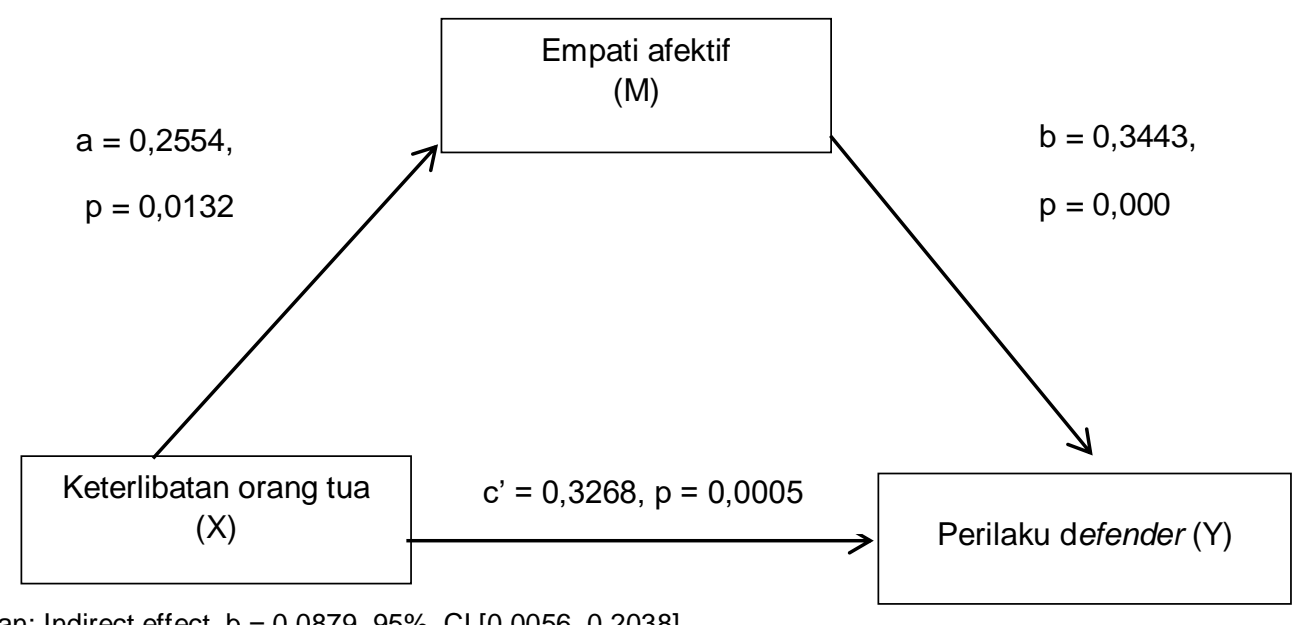

Keterangan: Indirect effect, b = 0,0879, 95\%, Cl [0,0056, 0,2038]

Gambar 1 Model $4 \mathrm{~F}$ - Hayes: keterlibatan orang tua terhadap peran defender yang dimediasi empati afektif 
Tabel 3 Hasil uji regresi keterlibatan orang tua terhadap perilaku defender dan empati kognitif terhadap perilaku defender

\begin{tabular}{|c|c|c|c|c|c|c|}
\hline \multirow[t]{2}{*}{ Dependen Variable } & \multirow[t]{2}{*}{$\mathrm{R} 2$} & \multicolumn{2}{|c|}{ Unstandardized coefficents } & $\begin{array}{l}\text { Standardized } \\
\text { Coeffiecients }\end{array}$ & $\mathrm{F}$ & $\mathrm{p}$ \\
\hline & & $\beta$ & Standar Error & Beta & & \\
\hline $\begin{array}{l}\text { Keterlibatan orang } \\
\text { tua }\end{array}$ & 0,127 & 0,415 & 0,096 & 0,357 & 18,680 & 0,000 \\
\hline Empathy affective & 0,038 & 0,310 & 0,087 & 0,196 & 12,664 & 0,000 \\
\hline
\end{tabular}

Lebih lanjut, hasil analisis seperti yang tersaji pada Gambar 2 menggambarkan bahwa keterlibatan orang tua masih berpengaruh lebih kuat dan positif terhadap perilaku defender dengan $\mathrm{B}=0,3536, \mathrm{t}=3,4871, \mathrm{p}<0,01$. Nilai indirect effect membuktikan bahwa tidak ada mediasi empati kognitif pada hubungan keterlibatan orang tua dengan defender $\mathrm{B}=0,0611, \quad \mathrm{LLCl}=-0,0173, \quad \mathrm{ULCl}=0,1479$. Artinya, keterlibatan orang tua tetap memiliki pengaruh langsung terhadap perilaku defender.

\section{PEMBAHASAN}

Defender merupakan individu yang berupaya aktif untuk menghentikan peristiwa perundungan dengan cara mendukung, menghibur, dan menolong korban dengan cara menghadapi pelaku atau mencari bantuan dari orang dewasa (Bellmore et al., 2012; Salmivalli et al., 1996; Thornberg et al., 2012). Hasil penelitian menunjukkan bahwa sebagian besar remaja dalam penelitian ini melakukan tindakan untuk menolong korban dalam peristiwa perundungan. Sebagaimana yang dijelaskan oleh Bellmore et al. (2012) yang meneliti siswa SD dalam konteks perundungan, penelitian tersebut mendapati semakin bertambahnya usia siswa maka akan semakin sedikit individu

yang mengambil peran sebagai defender. Hasil penelitian Damanik dan Djuwita (2019) yang menggunakan remaja SMA sebagai partisipan penelitiannya mendapati bahwa sebagian besar remaja SMA tersebut memilih untuk tidak melakukan apa-apa ketika menyaksikan peristiwa perundungan.

Dalam penelitian ini didapati bahwa siswa SMP (remaja awal) lebih banyak yang bertindak sebagai defender (menolong korban) ketika menyaksikan peristiwa perundungan di sekolahnya. Artinya, siswa SMP yang berada pada tahap usia remaja awal ini menunjukkan bahwa perannya sebagai defender masih tinggi. Hal inilah yang harus terus dipelihara melalui keterlibatan orang tua yang terus mengembangkan empati anak agar saat mereka beranjak ke tahap usia selanjutnya masih tetap berpegang pada peran sebagai defender ketika menyaksikan peristiwa perundungan di sekitarnya. Oleh karena itu, penelitian ini bertujuan untuk membuktikan empati dalam memediasi pengaruh keterlibatan orang tua terhadap peran defender pada usia remaja awal ini (siswa SMP). Hasil penelitian ini mendapati bahwa keterlibatan orang tua memengaruhi secara positif perilaku defender. Hasil penelitian ini sejalan dengan hasil penelitian yang dilakukan oleh Valdez-Cuervo et al. (2018) yang mendapati bahwa pengasuhan yang positif dari orang tua sangat penting untuk menstimulasi emosi moral dan peran sebagai defender.

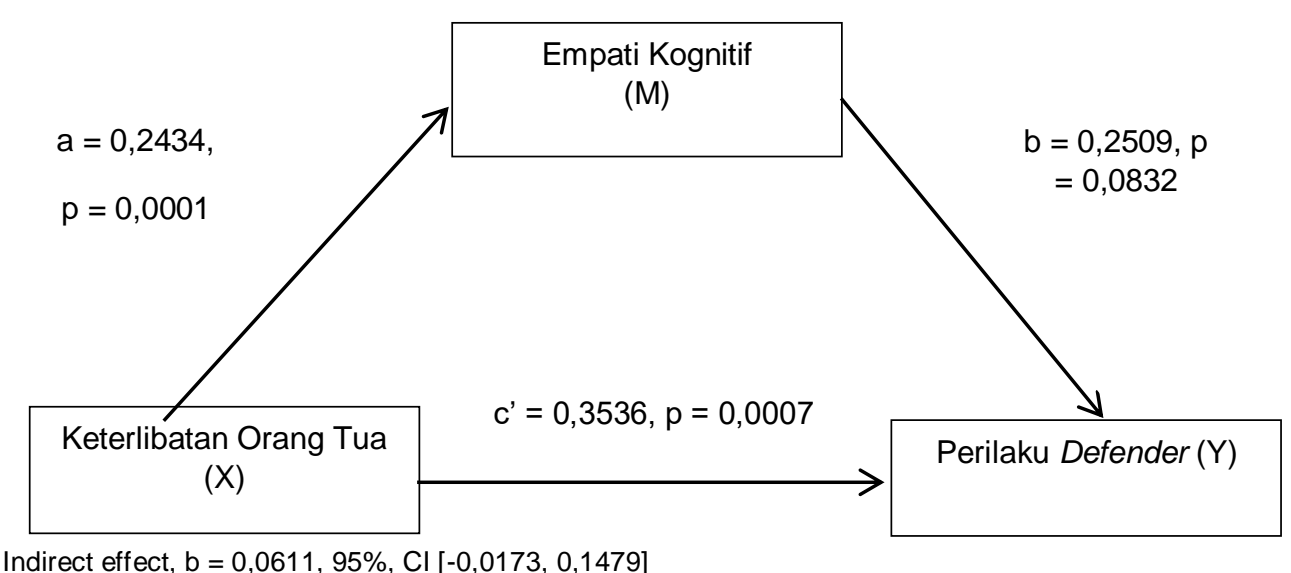

Keterangan: Indirect effect, $\mathrm{b}=0,0611,95 \%, \mathrm{Cl}[-0,0173,0,1479]$

Gambar 2 Model 4 F - Hayes: keterlibatan orang tua terhadap peran defender yang dimediasi empati kognitif 
Lebih lanjut, sejumlah hasil riset lainnya juga menegaskan bahwa keluarga, khususnya pengasuhan yang positif, merupakan pendorong perilaku yang mengarahkan remaja untuk mengambil peran sebagai defender dalam peristiwa perundungan (Carlo, McGinley, Hayes, \& Martinez, 2012; Padilla-Walker et al., 2012).

Hasil penelitian ini dapat membantu memahami bahwa keterlibatan orang tua dapat meminimalisir tindakan perundungan pada anaknya yang berada di usia remaja awal. Keterlibatan orang tua dapat membuat anak yakin untuk menolak tindakan perundungan baik pada dirinya maupun orang lain (termasuk temannya) karena anak merasa yakin bahwa orang tuanya mendukung dan menginginkannya untuk melakukan hal tersebut, yaitu membela diri dan temannya dari perilaku perundungan.

Keberhasilan atau kegagalan peran keluarga menjadi penentu pembentukan diri remaja karena keluarga kerap dilihat sebagai tempat yang optimal agar anak dapat belajar untuk memahami perspektif dan membuat penilaian moral dari fase awal dalam kehidupan mereka (Yoo, Feng, \& Day, 2013). Apabila hubungan dengan orang-orang terdekat seperti keluarga terjalin dengan baik maka individu atau remaja akan cenderung berperilaku baik juga, begitu pula sebaliknya (Nic kerson, Mele, \& Princiotta, 2008). Interaksi dengan orang tua maupun saudara kandung akan menyebabkan anak belajar cara untuk dapat berperilaku secara tepat dalam konteks sosial. Oleh karena itu, eksplorasi tentang cara-cara keluarga mendukung perilaku tersebut menjadi sangat penting (Criss, Smith, Morris, Liu, \& Hubbard, 2017).

Hasil penelitian ini menunjukkan bahwa keterlibatan orang tua dalam mengembangkan empati pada anak remajanya merupakan satu cara dalam mendukung perilaku sebagai defender. Hasil penelitian sebelumnya menyatakan bahwa keterlibatan orang tua merupakan faktor yang memengaruhi perilaku perundungan secara signifikan (Espelage, 2014; Shetgiri, Lin, Avila, \& Flores, 2012) dan orang tua dari pelaku perundungan biasanya tidak secara aktif melibatkan dirinya dalam kehidupan anaknya (Espelage, 2014). Empati menjadi salah satu nilai penting untuk dikembangkan secara langsung oleh orang tua dalam melibatkan diri pada kehidupan remajanya. Penelitian ini juga menunjukkan bahwa sumbangan empati afektif lebih besar dibandingkan dengan empati kognitif terhadap peran defender dalam peristiwa perundungan. Hasil ini sejalan dengan penelitian Poteat dan Espelage (2005) yang menjelaskan bahwa keprihatinan empatik (empati afektif) lebih dapat memperkuat motivasi untuk membela korban. Temuan yang kurang lebih sama terdapat pada sejumlah penelitian terdahulu yang meneliti pengaruh empati afektif dan kognitif terhadap peran defender, yaitu hanya empati afektif yang diketahui memprediksi perilaku membela (Barchia \& Bussey, 2011; Caravita, Di-Blasio, \& Salmivalli, 2009; Poyhonen, Juvonen, \& Salmivalli, 2010).

Remaja dengan kapasitas empati afektif yang tinggi mampu untuk berbagi perasaan atau status emosi dengan orang lain. Empati afektif terjadi ketika individu mampu merespon isyarat terbuka yang menunjukkan keadaan emosi orang lain, misalnya kualitas suara dan ekspresi wajah maupun menyimpulkan keadaan orang lain berdasarkan isyarat tidak langsung, misalnya sifat orang lain (Cohen, 1996). Keberadaan dimensi afektif inilah yang memotivasi perilaku prososial dan menurunkan perilaku agresif terhadap orang lain. Hati nurani mereka akan mudah terusik ketika menyaksikan kemalangan orang lain, termasuk korban perundungan yang kemudian memunculkan perilaku prososial (Stel, van Baaren, \& Vonk, 2008).

Empati afektif juga didapati memediasi sebagian hubungan keterlibatan orang tua dengan defender. Artinya, keterlibatan orang tua tetap memiliki pengaruh langsung terhadap perilaku defender meski terdapat pengaruh mediasi dari empati afektif. Ketika orang tua makin terlibat dalam kehidupan anaknya maka kecenderungan anak untuk berperan sebagai defender makin tinggi. Oleh karena itu, orang tua harus melibatkan diri dalam memberikan dukungan otonomi, yaitu dengan cara menghargai pandangan anak dan menggunakan teknik yang mendorong pilihan agar remaja mampu partisipasi dalam membuat keputusan untuk membela korban. Selain itu, orang tua juga perlu membangun lingkungan rumah dan sikap positif terhadap sekolah dan pembelajaran pada anak agar remaja memiliki kesan yang positif pula terhadap sekolah, guru, dan teman-temannya. Terakhir, orang tua harus dapat memberikan kehangatan pada anak, yaitu dengan merespon dan memberikan perhatian untuk anak remajanya. Hal-hal tersebut akan membuat anak merasa dipedulikan sehingga mereka pun akan terlatih untuk peka dan peduli terhadap status emosi atau perasaan korban perundungan. Pada akhirnya, remaja akan mampu tergerak untuk 
membela korban perundungan, mulai dari cara sederhana yaitu dengan menghibur korban, melapor pada pihak otoritas sekolah, sampai mereka berani untuk melawan pelaku apabila tidak ada cara lain.

Sementara itu, empati kognitif didapati tidak memediasi hubungan keterlibatan orang tua dengan defender. Gini, Albiero, Benelli, dan Altoe (2007) menjelaskan definisi empati afektif dan empati kognitif menurut dimensi yang dikemukakan oleh Davis (2018), yaitu masingmasing dimensi tersebut memiliki dua subdimensi. Hasil dari kajian meta-analisis yang dilakukan oleh Jolliffe dan Farrington (2006) menunjukkan ada hubungan negatif antara empati dan perilaku menyerang (offending). Hubungan ini didapati lebih kuat pada empati kognitif dibanding empati afektif serta lebih kuat pada usia remaja dibandingkan usia setelahnya. Berkaitan dengan peran empati kognitif ini, Joliiffe dan Farrington (2006) menyebutkan bahwa kemampuan untuk memahami sudut pandang orang lain sangat menguntungkan untuk melakukan tindakan perundungan yang efektif dan merekurit orang lain untuk ikut melakukan perundungan.

\section{SIMPULAN DAN SARAN}

Berdasarkan hasil penelitian, keterlibatan orang tua dapat mengembangkan empati pada anak yang mulai menginjak remaja untuk berani berperan sebagai defender dalam membela korban perundungan. Artinya, penting bagi orang tua untuk tetap melibatkan diri dalam kehidupan anaknya meskipun mereka sudah beranjak remaja. Orang tua yang mampu secara konsisten menunjukkan kehangatan dalam berinteraksi dengan remajanya akan membuat anak mampu merasakan kesulitan orang lain (empati afektif), termasuk perasaan korban dalam peristiwa perundungan. Keterlibatan orang tua dan kemampuan merasakan emosi korban perundungan inilah yang kemudian dapat membuat remaja berani untuk berperan sebagai defender, yaitu remajaremaja yang berani bersuara untuk membantu korban perundungan, khususnya perundungan di sekolah.

Implikasi penelitian ini berhubungan dengan kontribusi peran orang tua untuk melibatkan diri dalam kehidupan anaknya yang beranjak remaja baik dalam hal pendidikan sekolah maupun pergaulan agar anak mau terbuka untuk memberikan informasi mengenai tindakan perundungan yang terjadi. Dengan demikian, orang tua dapat senantiasa memantau dan mendorong anak remajanya untuk mau menolong dan membela temannya ketika terjadi peristiwa perundungan. Dalam hal ini, keterlibatan orang tua dalam mengembangkan empati anak sangat diperlukan agar remaja mau peduli akan nasib korban perundungan, termasuk berani mempertahankan dirinya agar tidak menjadi korban berikutnya.

Penelitian selanjutnya diharapkan dapat lebih memperluas wilayah penelitian yang dapat melibatkan jumlah maupun jenis sekolah yang lebih bervariasi. Selain itu, peneliti selanjutnya dapat mengaitkan dengan peran peer group (teman sebaya) di sekolah sebagai salah satu intervensi agar dapat meningkatkan empati antarsiswa dalam memotivasi mereka sebagai defender dalam menghadapi peristiwa perundungan di sekolah.

\section{DAFTAR PUSTAKA}

[KPAl] Komisi Perlindungan Anak Indonesia. (2019). Catatan KPAl, Kekerasan Anak di Pendidikan Jakarta Tinggi. Jakarta, ID: KPAI

Barchia, K., \& Bussey, K. (2011). Predictors of student defenders of peer aggression victims: Empathy and social cognitive factors. International Journal of Behavioral Development, 35(4), 289-297. doi:https:// doi:10.1177/0165025410396746.

Bellmore, A., Ma, T. L., You, J., \& Hughes, M. (2012). A two-method investigation of early adolescents' responses upon witnessing peer victimization in school. Journal of Adolescence, 35, 1265-1276. doi:https:// doi:10.1016/j.adolescence.2012.04.012.

Caravita, S. C. S., Di-Blasio, P., \& Salmivalli, C. (2009). Unique and interactive effects of empathy and social status on involvement in bullying. Social Development, 18, 140163. doi:https://dx.doi.org/10.1111/j.14679507.2008.00465.x.

Card, N. A., Stucky, B. D., Sawalani, G. M., \& Little, T. D. (2008). Direct and indirect aggression during childhood and adolescence: A meta-analytic review of gender differences, intercorrelations, and relations to maladjustment. Child Development, 79(5), 1185-1229. doi:https: //doi:10.1111/j.1467-8624.2008.01184.x.

Carlo, G., McGinley, M., Hayes, R., \& Martinez, M. M. (2012). Empathy as mediator of the relations between parent and peer attachment and prosocial and physically aggressive behavior in Mexican American college students. Journal of Social and 
Personal Relationships, 29, 337-357. doi:https://doi:10.1177/0265407511431181

Cho, S., Glassner, S., \& Lee, J. M. (2019). Impact of low self-control, parental involvement, and peer relationships on changes of bullying perpetration over time: A latent growth curve model of a sample of South Korean adolescents. Children and Youth Services Review, 104, 104397. doi:https://doi:10.1016/j.childyouth.2019.10 4397.

Cohen, D., \& Strayer, J. (1996). Empathy in conduct-disordered and comparison youth. Developmental Psychology, 32(6), 988. doi:https://doi: 10.1037/00121649.32.6.988.

Criss, M. M., Smith, A. M., Morris, A. S., Liu, C., \& Hubbard, R. L. (2017). Parents and peers as protective factors among adolescents exposed to neighborhood risk. Journal of Applied Developmental Psychology, 53, 127-138. doi:https://doi: 10.1016/j.appdev.2017.10.004.

Damanik, G. N., \& Djuwita, R. (2019). Gambaran perundungan pada siswa tingkat SMA di Indonesia. Jurnal Psikogenesis, 7(1), 28-40. doi:https://doi: 10.24854/jps.v7i1.875.

Datta, P., Cornell, D., \& Huang, F. (2016). Aggressive attitudes and prevalence of bullying bystander behavior in middle school. Psychology in the Schools, 53(8), 804-816. $10.1002 /$ pits.21944

Erginoz, E., Alikasifoglu, M., Ercan, O., Uysal, O., Alp, Z., Ocak, S., ... \& Albayrak Kaymak, D. (2015). The role of parental, school, and peer factors in adolescent bullying involvement: Results from the Turkish HBSC 2005/2006 study. Asia Pacific Journal of Public Health, 27(2).

Espelage, D. L. (2014). Ecological theory: Preventing youth bullying, aggression, and victimization. Theory into Practice, 53(4), 257-264. 10.1080/00405841.2014.947216.

Gini, G., Albiero, P., Benelli, B., \& Altoe, G. (2007). Does empathy predict adolescents' bullying and defending behavior? Aggressive Behavior: Official Journal of the International Society for Research on Aggression, 33(5), 467-476. doi:https://doi: 10.1002/ab.20204.

Gini, G., Pozzoli, T., \& Bussey, K. (2014). The role of individual and collective moral disengagement in peer aggression and bystanding: A multilevel analysis. Journal of Abnormal Child Psychology, 43, 441452. doi:https://doi:10.1007/s10802-0149920-7.

Jenkins, L. N., Demaray, M. K., Fredrick, S. S., \& Summers, K. H. (2016). Associations among middle school students' bullying roles and social skills. Journal of School Violence, 15(3), 259-278. doi:https://doi 10.1080/15388220.2014.986675.

Jolliffe, D \& Farrington, D. P. (2006). Development and validation of the basic empathy scale. Journal of Adolelescence, 29, 589-611. doi:https://doi 10.1016/ j.adolescence.2005.08.010.

Jungert, T., Piroddi, B. \& Thornberg. (2016). Early adolescents' motivations to defend victims in school bullying and their perceptions of student-teacher relationship: A self-determination theory approach. Journal of Adolescence, 53, 7590. doi:https://doi 10.1016/j.adolescence .2016.09.001.

Koyanagi, A., Oh, H., Carvalho, A. F., Smith, L., Haro, J. M., Vancampfort, D., .Brendon, S., \& DeVylder, J. E. (2019). Bullying victimization and suicide attempt among adolescents aged 12-15 years from 48 countries. Journal of the American Academy of Child \& Adolescent Psychiatry, 58(9), 907-918. doi:https://doi 10.1016/j.jaac.2018.10.018.

Lai, F. H., Siu, A. M., \& Shek, D. T. (2015). Individual and social predictors of prosocial behavior among Chinese adolescents in Hong Kong. Frontiers in pediatrics, 3, 39.

Lambe. L. J., Hudson, C. C., Craig, W. M. \& Pepler, D. J. (2017). Does defending come with a cost? Examining the psychosocial correlates of defending behavior among bystanders of bullying in a Canadian sample. Child Abuse \& Neglect, 65, 112123. doi:https://doi:10.1016/j.chiabu .2017.01.012.

Lawrence, E. J., Shaw, P., Baker, D., BaronCohen, S., \& David, A. S. (2004). Measuring empathy: Reliability and validity of the empathy quotient. Psychological Medicine, 34(5), 911-920. doi:https:// doi:10.1017/S0033291703001624.

Marela, G., Wahab, A., \& Marchira, C. R. (2017). Bullying verbal menyebabkan depresi pada remaja SMA di Kota Yogyakarta. Berita Kedokteran Masyarakat, 33(1), 43-48.

Nickerson, A. B., Mele, D., \& Princiotta, D. 
(2008). Attachment and empathy as predictors of roles as defenders or outsiders in bullying interactions. Journal of School Psychology, 46(6), 687-703. doi:https://doi:10.1016/j.jsp.2008.06.002.

Padilla-Walker, L. M., Carlos, G., Christensen, K. J., \& Vorgason, J. B. (2012). Bidirectional relations between authoritative parenting and adolescents' prosocial behaviors. Journal of Research on Adolescence, 22, 400-408. doi:https://doi:10.1111/j.1532-7795. 1011.00807.x.

Patterson, L. J., Allan., \& Cross, D. (2017). Adolescent bystander behavior in the school and online environments and the implications for interventions targeting cyberbullying. Journal of School Violence, 16(4), 361-375. doi:https://doi.org/10.1080 /15388220.2016.1143835.

Poteat, V. P., \& Espelage, D. L. (2005). Exploring the relation between bullying and homophobic verbal content: The homophobic content agent target (HCAT) Scale. Violence and victims, 20(5), 513528. doi:https://doi:10.1891/vivi.2005 .20.5.513.

Pöyhönen, V., Juvonen, J., \& Salmivalli, C. (2010). What does it take to stand up for the victim of bullying? The interplay between personal and social factors. Merrill-Palmer Quarterly (1982-), 143-163.

Pronk, J., Olthof, T., \& Goosseens, F. A. (2015). Differential personality correlates of early adolescents' bullying-related outsider and defender behavior. Journal of Early Adolescence, 35, 1069-1091. doi:https://doi.org/10.1177/0272431614549 628

Rigby, K., \& Johnson, B. (2005). Student bystanders in Australian schools. Pastoral Care in Education, 23(2), 10-16. doi:https://doi:10.1111/j.0264-3944.2005 .00326.x.

Rigby, K., \& Johnson, B. (2006). Expressed readiness of Australian school children to act as bystanders in support of children who are being bullied. Educational Psychology, 26(3), 425-440. doi:https://doi.org/10/1080/0144341050034 22047.

Rivers, I., \& Noret, N. (2013). Potential suicide ideation and its association with observing bullying at school. Journal of Adolescent Health, 53(1), S32-S36. doi:https:// doi:10.1016/j.jadohealth.2012.10.279

Robbins, R. J. (1994). An assessment of perceptions of parental autonomy support and control: Child and parent correlates (Dissertation). New York, US: University of Rochester.

Rothon, C., Head, J., Klineberg, E., \& Stansfeld, S. (2011). Can social support protect bullied adolescents from adverse outcomes? A prospective study on the effects of bullying on the educational achievement and mental health of adolescents at secondary schools in East London. Journal of Adolescence, 34(3), 579-588. doi:https://doi:10.1016/ j.adolescence.2010.02.007.

Salmivalli, C. (1999). Participant role approach to school bullying: Implications for interventions. Journal of Adolescence, 22(4), 453-459. doi:https: //doi:10.1006/jado.1999.0239.

Salmivalli, C., Lagerspetz, K., Björkqvist, K., Österman, K., \& Kaukiainen, A. (1996). Bullying as a group process: Participant roles and their relations to social status within the group. Aggressive Behavior: Official Journal of the International Society for Research on Aggression, 22(1), 1-15. doi:https://doi:10.1002/(SICI)10982337(1996)22:1<1::AID-AB1>3.0.CO;2-T.

Shetgiri, R., Lin, H., Avila, R. M., \& Flores, G. (2012). Parental characteristics associated with bullying perpetration in US children aged 10 to 17 years. American journal of public health, 102(12), 2280-2286. doi:https://doi:10.2105/AJPH.2012.300725.

Smokowski, P. R., \& Kopasz, K. H. (2005). Bullying in school: An overview of types, effects, family characteristics, and intervention strategies. Children \& Schools, 27(2), 101-110. doi:https://doi: 10.1093/cs/27.2.101.

Solberg, M. E., \& Olweus, D. (2003). Prevalence estimation of school bullying with the Olweus Bully/Victim Questionnaire. Aggressive Behavior: Official Journal of the International Society for Research on Aggression, 29(3), 239268. doi:https://doi:10.1002/ab.10047.

Stel, M., van Baaren, R. B., \& Vonk, R. (2008). Effects of mimicking: Acting prosocially by being emotionally moved. European Journal of Social Psychology, 38, 965-976. doi:https://dx.doi.org/10.1002/ejsp.472

Stives, K. L., May, D. C., Pilkinton, M., Bethel., \& Eakin, D. K. (2018). Strategies to 
combat bullying: Parental responses to bullies, bystanders, and victims. Youth \& Society, 1-19. doi:https://doi 10.1177/0044118X18756491.

Storer, H. L., Casey, E. A., \& Herrenkohl, T. I. (2017). Developing "whole school" bystander interventions: The role of school-settings in influencing adolescents responses to dating violence and bullying. Children and youth services review, 74, 87-95. doi:https://doi: 10.1016/j.childyouth.2017.01.018.

Thornberg, R., Tenenbaum, L., Varjas, K., Meyers, J., Jungert, T., \& Vanegas, G. (2012). Bystander motivation in bullying incidents: To intervene or not to intervene?. Western Journal of Emergency Medicine, 13(3), 247. doi:https://doi: 10.5811/westjem.2012.3.11792.

Valdés-Cuervo, A.A., Alcántar-Nieblas, C., Martínez-Ferrer, B., \& Parra-Pérez, L. (2018). Relations between restorative parental discipline, family climate, parental support, empathy, and defenders in bullying. Children and Youth Services Review, 95, 152-159. doi:https://doi: 10.1016/j.childyouth.2018.10.015.

Van der Ploeg, R., Kretschmer, T., Salmivalli, C., \& Veenstra, R. (2017). Defending victims: What does it take to intervene in bullying and how is it rewarded by peers?. Journal of school psychology, 65, 1-10. /j.jsp.2017.06.002.

Vergara, G. A., Stewart, J. G., Cosby, E. A., Lincoln, S. H., \& Auerbach, R. P. (2019). Non-suicidal self-injury and suicide in depressed adolescents: Impact of peer victimization and bullying. Journal of affective disorders, 245, 744-749. doi:https://doi: 10.1016/j.jad.2018.11.084.

Yoo, H., Feng, X., \& Day, R. D. (2013). Adolescents' empathy and prosocial behavior in the family context: A longitudinal study. Journal of youth and adolescence, 42(12), 1858-1872. doi:https: //doi:10.1007/s10964-012-9900-6. 